\title{
Minimum Void Ratio Model Established from Tailings and Determination of Optimal Void Ratio
}

\author{
Shibo Li $\mathbb{D},{ }^{1,2}$ Hao Liang, ${ }^{1}$ Hao $\mathrm{Li}^{1}{ }^{1}$ Jianquan $\mathrm{Ma} \mathbb{D}^{1,},{ }^{1,2,3}$ and $\mathrm{Bin} \mathrm{Li}^{1,3}$ \\ ${ }^{1}$ College of Geology and Environment, Xi'an University of Science and Technology, Xi'an 710054, China \\ ${ }^{2}$ Shaanxi Provincial Key Laboratory of Geological Support for Coal Green Exploitation, Xi'an 710054, China \\ ${ }^{3}$ Laboratory of the Northern Qinghai-Tibet Plateau Geological Processes and Mineral Resources, Qinghai Geological \\ Survey Institute, Xining 810012, China
}

Correspondence should be addressed to Jianquan Ma; majianquan@xust.edu.cn

Received 17 June 2021; Accepted 14 August 2021; Published 2 September 2021

Academic Editor: José Luis Pastor

Copyright (C) 2021 Shibo Li et al. This is an open access article distributed under the Creative Commons Attribution License, which permits unrestricted use, distribution, and reproduction in any medium, provided the original work is properly cited.

\begin{abstract}
Minimum void ratio of tailings and its value change with fine content and are key design parameters for tailing consolidation and seepage stability. Based on the distribution of tailing grains with the sedimentary beach, we establish a minimum void ratio model for tailing grain in binary size, which requires only two parameters $(\varepsilon$ and $\omega)$. Calibrations of the model using 168 groups of tests (22 kinds of grain size ratios with 7-9 kinds of fine contents) show two parameters that are fitting for power function, and the exponent values increase with the dominant grain size expanded. Besides, the exponent values are related to the equivalent grain size ratio, dominant grain size, and shape characteristics. The minimum void ratios with fine content are predicted under the derived model. Good agreement was obtained between the predictions and measurements, and the average discrepancies are less than $10 \%$. And optimal void ratio and optimal fine content can be predicted, and the values are in good agreement with the experimental ones. Furthermore, based on the predicted optimal void ratio, the exponential relationship between the optimal void ratio and the equivalent grain size ratio may have no influence on the derived dominant grain size and shape characteristics. For tailings, further work is needed to verify if the derived exponential relationship between the optimal void ratio and the equivalent grain size ratio is valid.
\end{abstract}

\section{Introduction}

Over the last few decades, with the increase in the demand for minerals and metals, a large amount of mine tailings has been generated with the exploitation of mineral resources. In particular, the height and storage capacity of tailing dams have increased continuously during the past decades to meet the growing mine exploitation demand, which inevitably leads to the increase in the risk of tailing dam failure [1-7]. The tailings are commonly discharged in sand and slurry, forming with small grain size, large void ratio, high water content, and compressibility $[8,9]$. Due to different mining technologies and ore separation methods, tailings in different mining areas have a large difference in particle size distribution. For example, more than $60 \%$ of the tailings located in Baogang Iron Mine in Baotou City have a maximum grain size of up to $0.5 \mathrm{~mm}$ and less than $0.075 \mathrm{~mm}$ [10]. Fengshuigou tailings in Liaoning Province, which are also from iron ore, have a grain size basically distributed in the range of $0.075-2 \mathrm{~mm}$; the grain size of tailings over $2 \mathrm{~mm}$ only accounts for $0.97 \%$, and the grain size of tailings less than $0.075 \mathrm{~mm}$ accounts for less than 15\% [11]. From the investigation of such tailings as copper, lead-zinc, molybdenum, tungsten, and phosphogypsum, it was found that the grain size of tailings generally does not exceed $2 \mathrm{~mm}$. Most of the tailing investigations found that the tailing grains presented uneven size and distribution, which were also an important factor affecting the safety of tailing consolidation and permeability [12-15].

The minimum void ratio is one of the most widely used indexes in engineering practice and construction [16], and it has been well documented and can provide a reliable physical index for accelerating the consolidation and drainage of tailings $[14,17,18]$. Some early studies found that the 
minimum void ratio is influenced significantly by the grain size distribution and grain shape, and that both void ratios increase with decreasing mean grain size $[19,20]$. In their investigation on the void ratios of diverse natural soils and artificial sand-silt mixtures using the JIS method, Cubrinovski and Ishihara [21] showed that the minimum void ratio is strongly affected by the grain shape, the fine content, mean grain size, and grain size distribution. Later, salt content, saturation degree, and temperature changes were founded to affect either dry density or void ratio ([17, 22$25])$. And, it was also found that the sedimentary environment and the process of soil mixing different fine contents in the sand can affect the minimum void ratio [26, 27]. For tailings, the deposition and grain size composition are determined by the raw ore mineral, ore dressing process, and discharge mode, and theoretically, these will not change for the same mining area $([10,28])$. Meanwhile, the deposition of a tailing is mostly in a saturated state, and it is less affected by temperature and salinity. Based on the above research, grain shape and fine content will become important factors for determining the minimum void ratio of tailings.

In the research of natural and crushed sands, the idea was proposed that the macroscale behaviour of the soil mass such as packing density, stiffness, and strength can affect grain shape [26]. $\mathrm{Ng}$ et al. [29] used the discrete element method for describing the relationship between void ratio and fine contents and proved that the grain shape factor has an influence on the initial modulus but not on the relationship between void ratio and fine content. However, grain shape has a noteworthy influence on the value of the minimum void ratio, which is generally lower for more spherical grains and higher for less spherical (or more angular) grains [30]. It can be seen that if there is a large difference in grain shape, the impact on the void ratio will be significant.

For another important factor, namely, fine content, in the engineering practice, the extensive research in the field of concrete mixes was carried out to show the influence of fine content on the magnitude of minimum void ratio at the earliest [31]. Subsequently, it also has been confirmed that the void ratio will be affected by the change of fine content in the soil foundation, slope, and coarse grain [27, 32-34]. Kuerbis [35] has found that there is the nonlinear relationship between void ratio and fine content, and the mechanical behaviour of soil was affected. Thevanayagam [36], Thevanayagam and Mohan [37], Thevanayagam et al. [38], and Thevanayagam [39] studied the relationship of fine content and void ratio and analyzed the relationship of stress-strain response, shear strength, and resistance to liquefaction with silty sand. Chaney et al. [40] and Chang et al. [41] found that fine content plays an important role in determining the sand structure and the consequent minimum and maximum void ratios, and they verified the linear relationship between the maximum and the minimum void ratios of a sand-silt mixture. Chang et al. [30] developed a mathematical model to predict the minimum void ratio for sand-silt mixtures with any amount of fine content. In view of this, an extended model from binary-sized mixtures to multisized mixtures was developed by Chang and Deng [42]. And Zhang et al. [15], based on the above research results, developed a nonlinear model for the prediction of the void ratio of granular soils with arbitrary grain size distributions. Xia et al. [43] found that the shear stress-strain curves of the sand clay mixtures gradually shifted from a strain-softening behaviour to a strain-hardening behaviour as the sand content increased, and the shear wave velocity decreased continuously with the increase in sand content until the sand skeleton had formed.

Given the particularity of tailing grain size distribution, which is disordered, it is necessary to understand the quantitative relationship between the grain size and void ratio of tailings, so as to provide a guarantee for the safe operation of tailings. In view of this, to establish a minimum void ratio model for tailing grain in binary size, combined with tailing grain shape and grain size distribution, we will begin with the analysis of the linear model. Then, the model will be extended to include the concept of optimal void ratio and optimal fine content. Based on this postulation, we formulate a nonlinear governing equation of minimum void ratio considering two mechanisms of tailing grain mixing. Finally, the developed new model is verified for its accuracy and applicability by comparing predicted and measured results on the minimum void ratio corresponding to different tailing grain size ratios. Besides, another nonlinear model for predicting the optimal void ratio of tailings with an arbitrary grain size ratio is obtained. The results show that the agreement between measured and predicted results is very good for the proposed nonlinear model.

\section{Development of a Minimum Void Ratio Model for Tailing Grain in Binary Size}

2.1. Model Hypothesis Based on Sedimentation and Characteristics of Tailings. As we know, tailing depositions mostly have an unconsolidated status and a disordered grain size distribution, and most of them are saturated [44]. To cater to different grain size tailings, for unit volume, we postulate that the tailing sediments are simplified to be composed of two grain sizes, coarse and fine, denoted as $D$ and $d$. According to the grain size distribution of tailing sediments in the literature and in this paper, the range of grain size is distributed between 0 and $2 \mathrm{~mm}$ [15, 17, 45-47]. The tailings cover a range of sand, silt, and clay size. In the same mining area, the dressing process is the same, the shape of grain is similar, and the differences of tailings in shape were only between sand and silt-clay. For convenience, it is assumed that tailing grains are circular with two different sizes, and the volume of tailings is denoted as $V_{\mathrm{G} 1}$ for coarse grains and $V_{\mathrm{G} 2}$ for fine grains. As we know, soil is formed by weathering and geologic processes and the transportation of sediments, and it consists of solid grains and the void spaces between the grains. Tailings in the pond are mainly saturated and unconsolidated, and the deposition mode is similar to that of soil, so the tailings can be simplified as a two-phase system of void space $\left(V_{\mathrm{V}}\right)$ and solid grains $\left(V_{\mathrm{G}}\right)$, and $V_{\mathrm{G}}=V_{\mathrm{G} 1}+V_{\mathrm{G} 2}$. For the solid grains, the volume fractions are, respectively, $x_{1}$ for coarse grains and $x_{2}$ for fine grains $\left(x_{1}+x_{2}=100 \%\right)$. And the minimum void ratios of monosized grain fraction are denoted $e_{1}$ 
(coarse grains) and $e_{2}$ (fine grains). On the basis of the above analysis and hypothesis, tailings formed by coarse-fine grains and voids can be divided into two types: coarse component-dominated tailings and fine componentdominated tailings.

2.2. Coarse Component-Dominated Tailings. Define and develop minimum void ratio, a nondimensional volume relationship that is suitable for coarse-grain-dominated tailings (Figure 1). First, considering tailings composed of pure coarse grains and voids, the void ratio is expressed as follows:

$$
e_{\min }=e_{1}=\frac{V_{\mathrm{V} 1}}{V_{\mathrm{G} 1}}
$$

Then, coarse grain limited status was formed with the addition of fine grains into the void without altering tailing volume, and the minimum void ratio can be calculated as follows:

$$
e_{\mathrm{min}}=\frac{V_{\mathrm{V}}}{V_{\mathrm{G} 1}+V_{\mathrm{G} 2}} \text {. }
$$

However, the tailing volume was changed with adding fine grains, and the minimum void ratio is as follows:

$$
e_{\min }=\frac{V_{\mathrm{V}}}{V_{\mathrm{G} 1}+V_{\mathrm{G} 2}}=\frac{V_{\mathrm{V} 1}+\Delta V_{\mathrm{V}}}{V_{\mathrm{G} 1}+V_{\mathrm{G} 2}} .
$$

Actually, the void spaces are altered and formed in the coarse grain general status.

In view of the addition of fine grains of tailing, the minimum void ratio altered due to void spaces diminished and the solid volume expanded. Chang et al. [30] gave a material constant $\alpha$ to describe these changes, and it is calculated as follows: $\alpha=-\left[1-\left(\Delta V_{\mathrm{V}} / V_{\mathrm{G} 2}\right)\right]$. follows:

Finally, the minimum void ratio can be expressed as

(1) When $x_{2}=0$, we express it through the pure coarse grain status

$$
e_{\min }=e_{1}
$$

(2) When $\alpha=0$, we express it through the coarse grain limited status

$$
e_{\min }=e_{1} \cdot\left(1-x_{2}\right)-x_{2}
$$

(3) When $\alpha \neq 0$, we express it through the coarse grain general status

$$
e_{\min }=e_{1} \cdot\left(1-x_{2}\right)-x_{2}+\alpha \cdot x_{2}
$$

2.3. Fine Component-Dominated Tailings. If the tailings are composed of pure fine grains, the void ratio is as follows:

$$
e_{\min }=e_{2}=\frac{V_{\mathrm{V} 2}}{V_{\mathrm{G} 2}} \text {. }
$$

With the addition of coarse grains, tailings change two different types of status. One status is the fine grain inclusions, which are separated by the coarse grains as an embedded body, named the fine grain limited status, and the void ratio is expressed as follows:

$$
e_{\min }=\frac{V_{\mathrm{V}}}{V_{\mathrm{G} 1}+V_{\mathrm{G} 2}}=\frac{V_{\mathrm{V} 2}}{V_{\mathrm{G} 1}+V_{\mathrm{G} 2}} .
$$

Close to the tailing dam, coarse grain content increases, original status is altered, single coarse ones tend to become clusters, and additional voids between the coarse grains, $\Delta$ $V_{\mathrm{V}}$, are created, forming the other status, named the fine grain general status. And the void ratio is expressed as follows

$$
e_{\min }=\frac{V_{\mathrm{V}}}{V_{\mathrm{G} 1}+V_{\mathrm{G} 2}}=\frac{V_{\mathrm{V} 2}+\Delta V_{\mathrm{V}}}{V_{\mathrm{G} 1}+V_{\mathrm{G} 2}} .
$$

Similarly, another parameter $\beta$ is assumed to describe the relationship between the increment of void volume and the fine grain volume [30], and $\beta=\Delta V_{\mathrm{V}} / V_{\mathrm{G} 1}$.

For each status, the minimum void ratio is as follows:

(1) When $x_{2}=1$ (Figures 2(a) and 2(d)), we have pure fine grain status

$$
e_{\min }=e_{2}
$$

(2) When $\beta=0$ (Figures 2(b) and 2(e)), we have fine grain limited status

$$
e_{\min }=e_{2} \cdot x_{2}
$$

(3) When $\beta \neq 0$ (Figures 2(c) and 2(f)), we have fine grain general status

$$
e_{\min }=e_{2} \cdot x_{2}+\beta \cdot\left(1-x_{2}\right)
$$

Theoretically, coarse-grain-dominated tailings and fine grain-dominated tailings can be transformed, and for tailing mixtures with arbitrary fine content, the minimum void ratio can be calculated by the equations of either type.

By changing the fine content $X_{2}$, two values of the minimum void ratio can be estimated from equation (6) and 


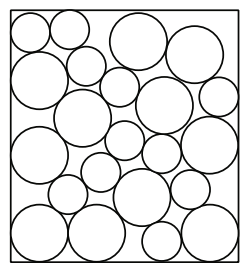

(a)

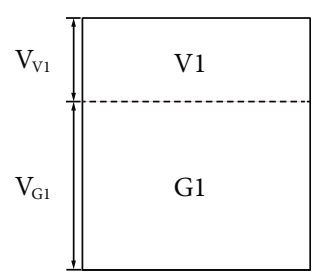

(d)

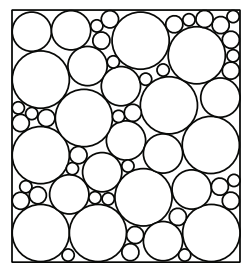

(b)

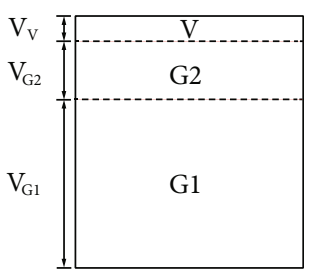

(e)

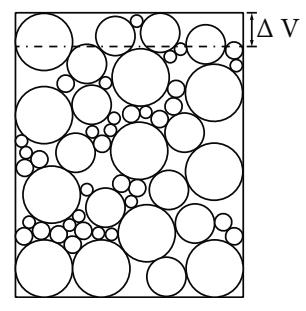

(c)

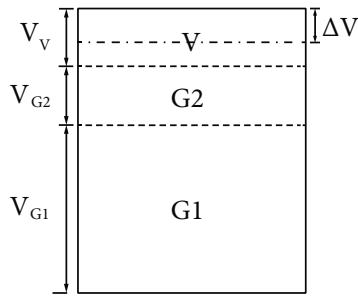

(f)

FIgURE 1: Diagram of coarse grain-dominated tailing deposits. (a-c) Schematics. (d-f) Phase diagrams. (a, d) Pure coarse grains of tailing. (b, e) With limited mixing tailing volume. (c, f) Mixing tailing volume in general.

equation (12), respectively, as shown in Figure 3, where the greater value that requires less energy to reach the state is the adopted one. And the minimum void ratio can be represented by the following equation:

$$
e_{\min }=e_{1} \cdot x_{1}+e_{2} \cdot x_{2}
$$

It is noted that the minimum void ratio should be within the triangular region of MP, line PN, and line NM. Line MO and line $\mathrm{NO}$ express the minimum void ratio versus the fine content of tailings that should theoretically conform to the rule of the inverted triangle rule, and $k_{\mathrm{a}}$ and $k_{\mathrm{b}}$ are represented as the slope of line MO and line NO.

The intersect point gives the optimal void ratio denoted as the lowest value of the minimum void ratio, $e_{\min -0}$, which corresponds to fine content that is the optimal fine content, $x_{2 \text { opt }}$.

$$
x_{2 \mathrm{opt}}=\frac{e_{1}-\beta}{1+e_{1}+e_{2}-\alpha-\beta} .
$$

When the fine content is less than the optimum, the coarse-grain tailing is the dominant component, and when the fine content is greater than the optimal fine content, the fine grain tailing is the dominant component.

It is noted that except for the minimum void ratio of monosized grains, $e_{1}$ and $e_{2}$, the optimal fine content corresponds with the parameter of $\alpha$ and $\beta$. According to equation (6) and equation (12), when the distribution of the minimum void ratio is on the boundary line of MP and $\mathrm{PN}, \alpha=\beta=0$. Otherwise, the minimum void ratio is distributed on the maximum limit line of NM, $\alpha=1+e_{2}, \beta=e_{1}$. The value of $\alpha$ is 0 to $1+e_{2}$ and $\beta$ is 0 to $e_{1}$.

For normalizing the parameter of $\alpha$ and $\beta$, two new variates $\varepsilon$ and $\omega$ are set between 0 and 1 , where $\varepsilon=(1-\alpha) /\left(1+e_{2}\right)$ and $\omega=(1-\beta) / e_{1}$. And equation (6) and equation (12) can be rearranged as follows:

$$
\begin{aligned}
& e_{\text {min }}=e_{1}\left(1-x_{2}\right)+e_{2} \cdot x_{2}-\varepsilon\left(1+e_{2}\right) \cdot x_{2}, \\
& e_{\text {min }}=e_{1}\left(1-x_{2}\right)+e_{2} \cdot x_{2}-\omega \cdot e_{1} \cdot x_{1} .
\end{aligned}
$$

The two parameters are functions of the geometric characteristics of the two constituents; thus, taking the derivative of equation (15) and equation (16), variates $\varepsilon$ and $\omega$ are expressed as follows:

$$
\begin{aligned}
& \varepsilon=\frac{e_{2}-e_{1}}{1+e_{2}}-\frac{1}{1+e_{2}}\left(\frac{d e_{\min }}{d x_{2}}\right), \\
& \omega=\frac{1}{e_{1}}\left(\frac{d e_{\min }}{d x_{2}}\right)-\frac{e_{2}-e_{1}}{e_{1}},
\end{aligned}
$$

where $d e_{\min } / d x_{2}$ represents $k_{\mathrm{a}}$ or $k_{\mathrm{b}}$, which can be acquired from the experimental results, and $\varepsilon$ (or $\omega$ ) and $d e_{\min } / d x_{2}$ have an obvious linear relation. Thus, the trends of $\varepsilon$ or $\omega$ are similar to those of $k_{\mathrm{a}}$ or $k_{\mathrm{b}}$, and the range of values of $\varepsilon$ or $\omega$ is between 0 and 1.

\section{Verification of the Model}

3.1. Material and Method. Based on the above theoretical analysis, selecting a tungsten tailing from Zhenan, Shaanxi Province, China, as the test material, they are all taken from a tailing mixture and the grain size distribution of tailings is shown in Figure 4. The test tailing grain size (GS) was sieved into 8 grain size ranges: $0-0.075 \mathrm{~mm}, 0.075-0.1 \mathrm{~mm}, 0.1-$ $0.15 \mathrm{~mm}, \quad 0.15-0.25 \mathrm{~mm}, \quad 0.25-0.3 \mathrm{~mm}, \quad 0.3-0.5 \mathrm{~mm}, \quad 0.5-$ $1 \mathrm{~mm}$, and 1-2 mm. To assess the impact of grain size and fine content on minimum void ratio, 8 kinds of grain size ranges are mixed, among which 7 kinds are fine grains (00.075 mm, 0.075-0.1 mm, 0.1-0.15 mm, 0.15-0.25 mm, 0.25- 


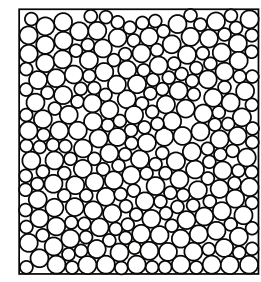

(a)

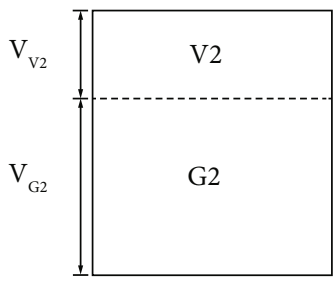

(d)

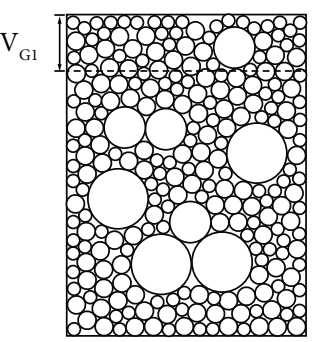

(b)

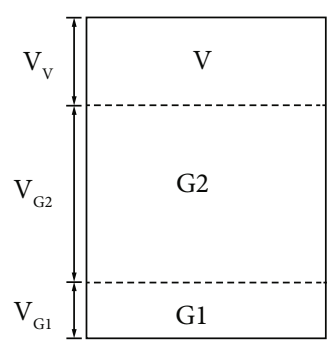

(e)

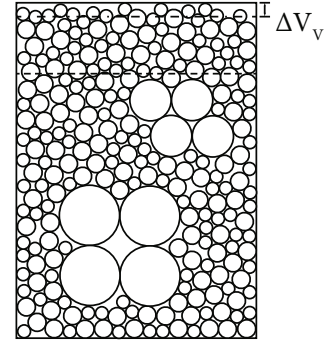

(c)

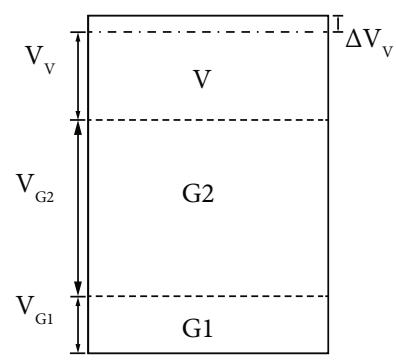

(f)

FIgURE 2: Diagram of fine-grain-dominant tailing mixture. $(a-c)$ Schematic diagrams. $(d-f)$ Phase diagrams. (a, d) Pure fine grains of tailing. (b, e) With limited mixing tailing volume. (c, f) Mixing tailing volume in general.

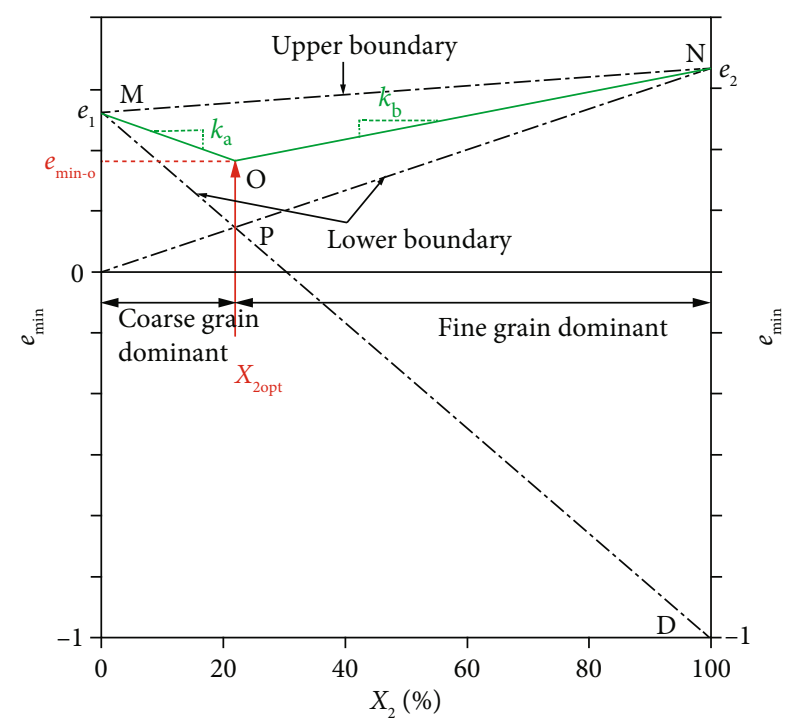

FIGURE 3: Characteristics of void ratio versus fine content for tailing mixtures. $e_{\min }$ is the minimum void ratio. $X_{2}$ is the fine content (\%). $e_{\text {min-o }}$ is the optimal void ratio. $X_{2 \text { opt }}$ is the optimal fine content. $k_{\mathrm{a}}$ is the slope for the left line, representing equation (6). $k_{\mathrm{b}}$ is the slope for the right line, representing equation (12). $\mathrm{MN}$ is the upper boundary. MP and NP are the lower boundaries.

0.3 mm, 0.3-0.5 mm, and 0.5-1 mm, named A, B, C, D, E, F, and $G$, respectively) and 4 kinds are coarse grains (1-2 mm, 0.5-1 mm, 0.3-0.5 mm, and 0.25-0.3 mm, named a, b, c, and $\mathrm{d}$, respectively). Then, 22 grain size patterns are set and the scheme of the experiments is shown in Table 1. Finally, minimum void ratios from 168 groups are acquired in different fine contents. These minimum void ratios for the 22 grain size patterns are determined by the Chinese standards of

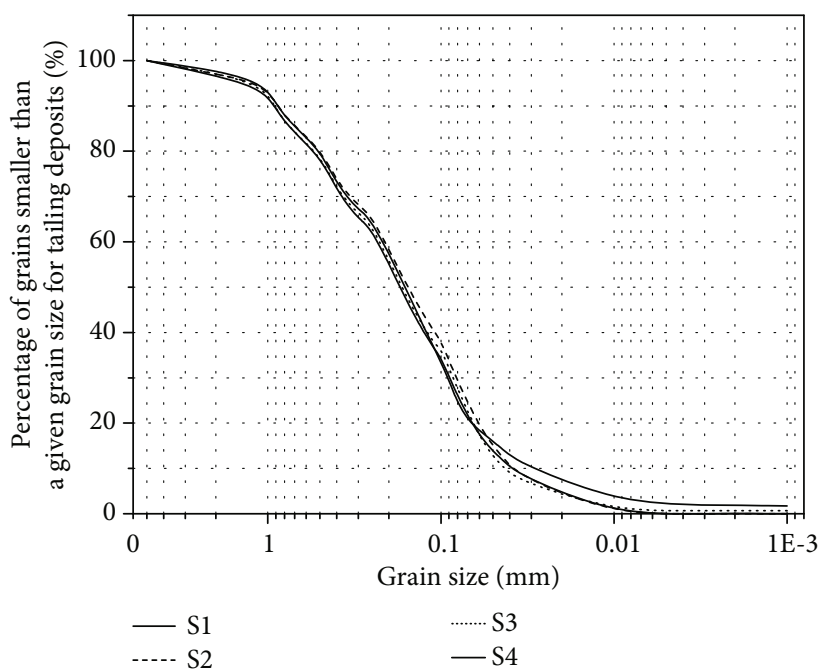

FIGURE 4: Grading curve of four original tailing deposits used in experiments.

technical code for geotechnical engineering of tailings embankment (GB50547-2010) and standard for geotechnical testing method (GB/T 50123-2019).

For each grain size range, the equivalent size was calculated by the grain geometric average:

$$
d_{\mathrm{e}}=\sqrt{d_{\max } \cdot d_{\min }}
$$

where $d_{\mathrm{e}}$ denotes the equivalent size of tailing grains, $d_{\max }$ is the maximum grain size of tailings, and $d_{\min }$ is the minimum grain size of tailings. And for the fine and coarse tailing mixture with 22 patterns, $d_{\mathrm{e}} / D_{\mathrm{e}}$ shows the equivalent 
TABLE 1: Scheme of the experiments.

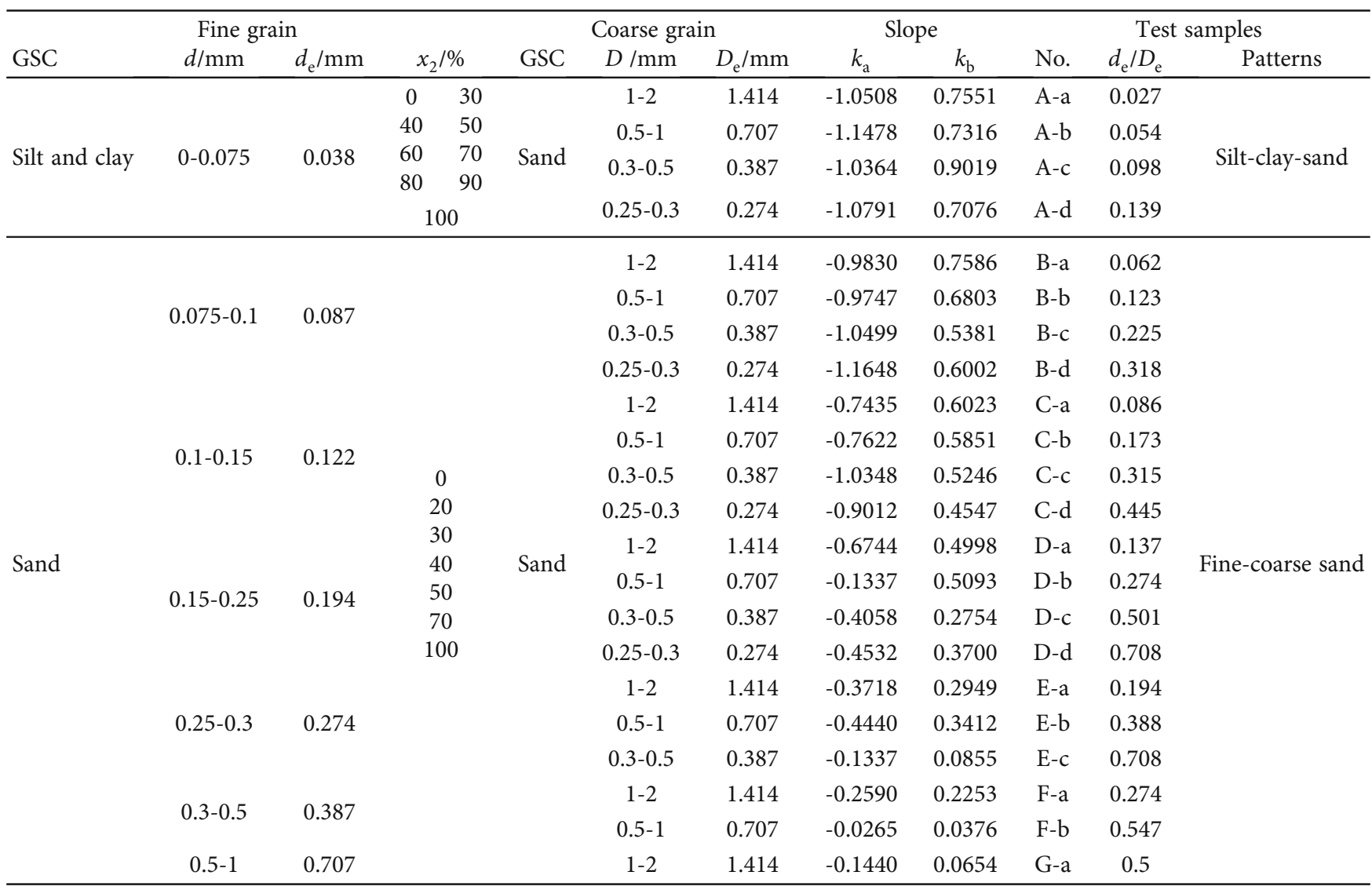

Note: $d$ denotes the fine grain of tailing deposits. $d_{\mathrm{e}}$ denotes the equivalent size of the fine grain of tailing deposits. $D$ denotes the coarse grain of tailing deposits. $D_{\mathrm{e}}$ denotes the equivalent size of coarse grain of tailing deposits. $x_{2}$ is the fine content in tailing deposits. GSC is the grain size classifications.

size ratio between fine grains and coarse grains of tailing deposits $[48,49]$.

3.2. Experimental Results. In order to see the relationship between the minimum void ratio $\left(e_{\min }\right)$ and the fine content $\left(X_{2}, \%\right)$ for tailings, the data for the minimum void ratio of 168 groups are plotted in Figure 5. The dashed lines were fitted from the measured minimum void ratios of monosized grain through the analysis in Figure 3. For 22 grain size patterns, the minimum void ratio should be within a triangular region bounded by a dashed line in theory. As observed from the measured results of the minimum void ratio versus fine content, although the minimum void ratio values conform to the triangle rule, the results are outside the inverted triangle range under the fine content exceeding by $60 \%$ for the patterns of silt-clay-sand tailings (Figures 5(a)-5(d)). For the patterns of fine-coarse sand tailings, the measured results are within the inverted triangle range (Figures $5(\mathrm{e})-5(\mathrm{v})$ )) The data points that are out of bounds can be attributed to the grain size classification from sand to silt-clay.

The test results of minimum void ratio versus fine content for different grain sizes show a different inverted triangle rule. For instance, if the coarse grain size is $1-2 \mathrm{~mm}$, and we mix the fine grain with the larger grain, the minimum void ratio comes closer to the upper boundary of the inverted triangle as shown in Figures 5(a), 5(e), 5(i), 5(m), $5(\mathrm{q})$, and 5(t). Oppositely, the value of the minimum void ratio comes closer to the bottom boundary of the inverted triangle as shown in Figures $5(\mathrm{~m})-5(\mathrm{p})$ if the fine grain size is $0.15-0.25 \mathrm{~mm}$ and we mix the coarse grain from small to large. This suggests that for binary grain size tailing that is coarse dominant, $-k_{\mathrm{a}}$ and $k_{\mathrm{b}}$ become less steep by mixing the fine grain size decrease; otherwise, $-k_{\mathrm{a}}$ and $k_{\mathrm{b}}$ become higher by mixing the coarse grain size smaller for the binary grain size tailing that is fine dominant (Table 1). On the other hand, this figure clearly shows the effect of equivalent grain size ratio $\left(d_{\mathrm{e}} / D_{\mathrm{e}}\right)$ on the trends of minimum void ratio. The lower the $d_{\mathrm{e}} / D_{\mathrm{e}}$, the closer is $e_{\min }$ to the bottom boundary of the inverted triangle (Figures 5(a)-5(c), and 5(e)); however, $e_{\min }$ approaches the upper boundary under a greater $d_{\mathrm{e}} / D_{\mathrm{e}}$ (Figures $5(\mathrm{o}), 5(\mathrm{p})$, and $\left.5(\mathrm{~s})-5(\mathrm{v})\right)$. The measurement results show that optimal void ratio values are the minimum void ratio corresponding to the fine content in the range of $20 \%-40 \%$, and these values are reduced with $d_{\mathrm{e}} / D_{\mathrm{e}}$ decreasing.

Different grain sizes correspond to different minimum void ratios. As shown in Figure 6, for the monosized tailing grain, the smaller the tailing grain size, the larger the value of the minimum void ratio; this has been proven by Chang et al. [30] with their research on sand-silt soil. And the range 


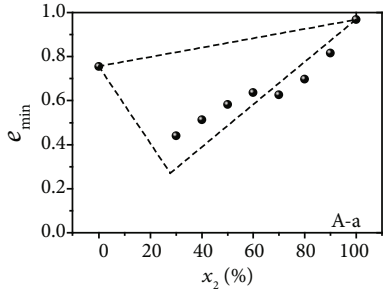

(a)

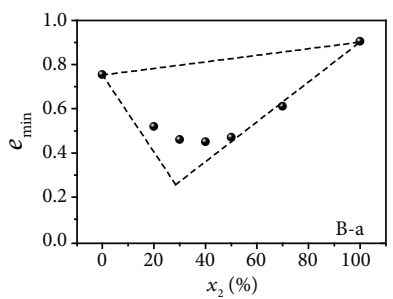

(e)

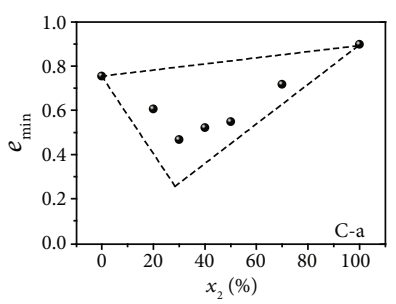

(i)

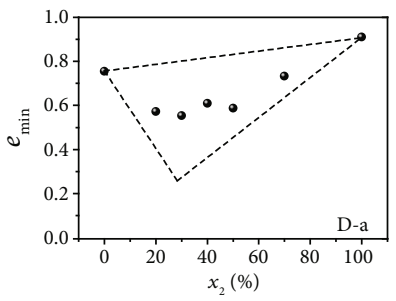

(m)

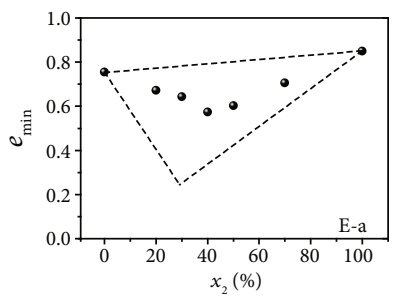

(q)

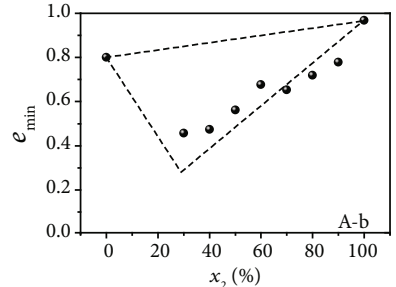

(b)

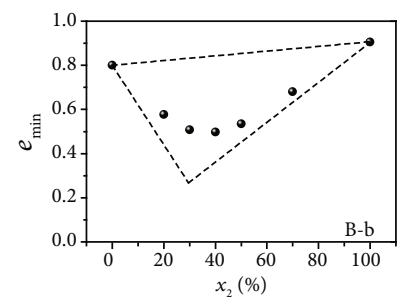

(f)

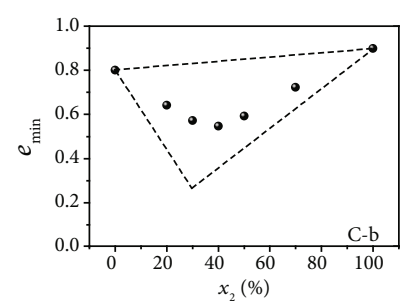

(j)

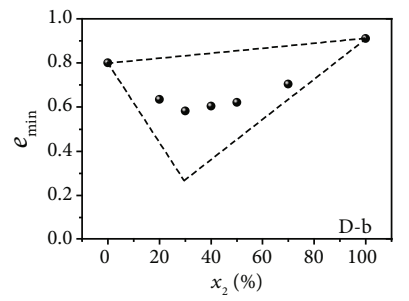

(n)

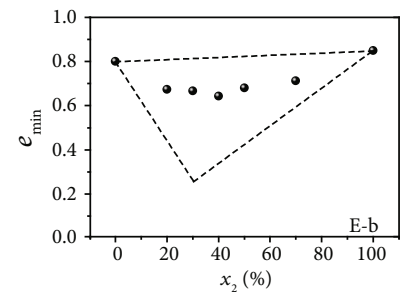

(r)

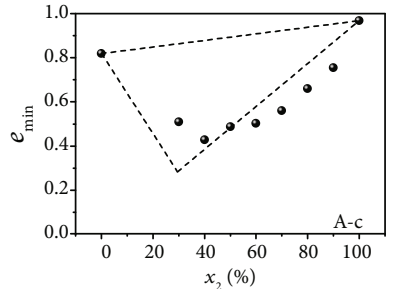

(c)

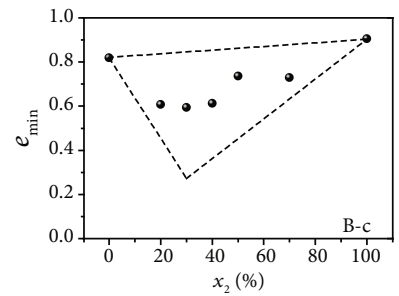

(g)

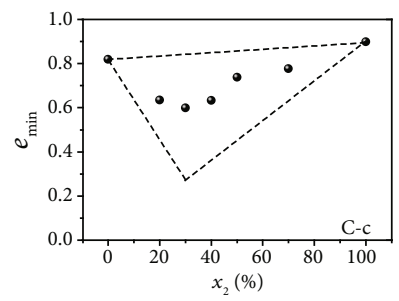

(k)

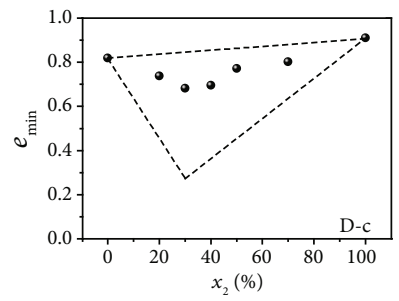

(o)

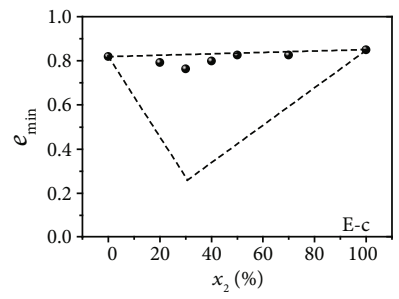

(s)

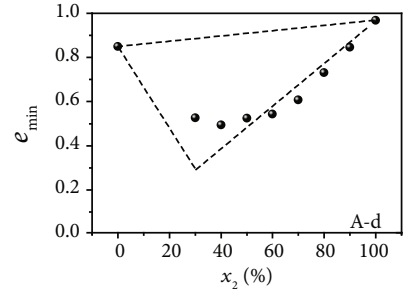

(d)

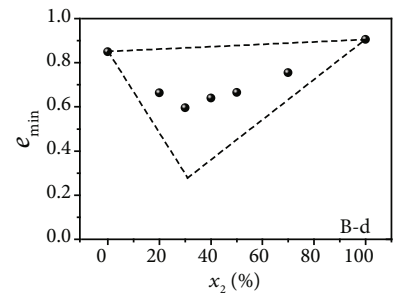

(h)

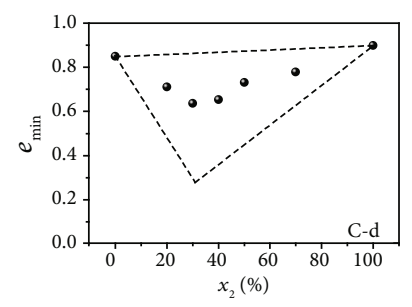

(l)

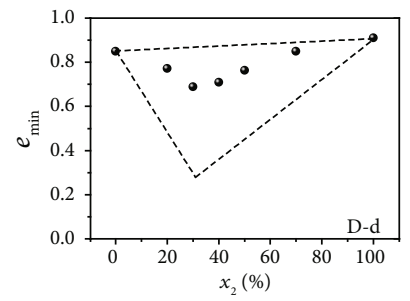

(p)

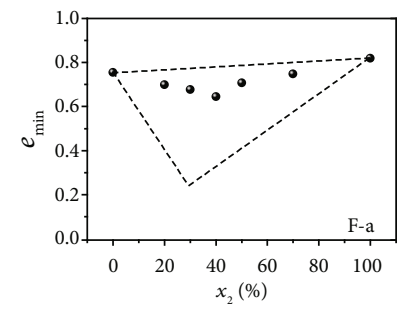

(t)

Figure 5: Continued. 


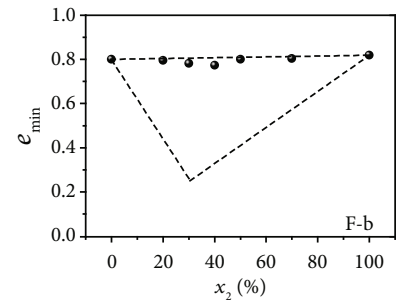

(u)

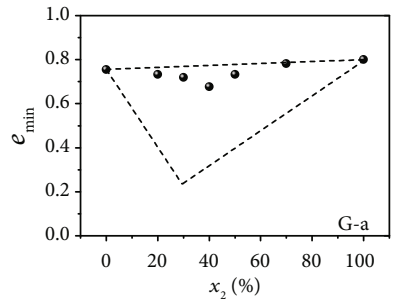

(v)

Figure 5: Measured minimum void ratio versus fine content for tailing mixture in 22 grain size patterns and the corresponding void ratio boundary. (a) Coarse grain tailing size is $0-0.075 \mathrm{~mm}$, and fine grain tailing size is $1-2 \mathrm{~mm}$. (b) Coarse grain tailing size is $0-0.075 \mathrm{~mm}$, and fine grain tailing size is $0.5-1 \mathrm{~mm}$. (c) Coarse grain tailing size is $0-0.075 \mathrm{~mm}$, and fine grain tailing size is $0.3-0.5 \mathrm{~mm}$. (d) Coarse grain tailing size is $0-0.075 \mathrm{~mm}$, and fine grain tailing size is $0.25-0.3 \mathrm{~mm}$. (e) Coarse grain tailing size is $0.075-0.1 \mathrm{~mm}$, and fine grain tailing size is $1-$ $2 \mathrm{~mm}$. (f) Coarse grain tailing size is $0.075-0.1 \mathrm{~mm}$, and fine grain tailing size is $0.5-1 \mathrm{~mm}$. (g) Coarse grain tailing size is $0.075-0.1 \mathrm{~mm}$, and fine grain tailing size is $0.3-0.5 \mathrm{~mm}$. (h) Coarse grain tailing size is $0-0.075 \mathrm{~mm}$, and fine grain tailing size is $0.25-0.3 \mathrm{~mm}$. (i) Coarse grain tailing size is $0.1-0.15 \mathrm{~mm}$, and fine grain tailing size is $1-2 \mathrm{~mm}$. (j) Coarse grain tailing size is $0.1-0.15 \mathrm{~mm}$, and fine grain tailing size is $0.5-1 \mathrm{~mm}$. (k) Coarse grain tailing size is $0.1-0.15 \mathrm{~mm}$, and fine grain tailing size is $0.3-0.5 \mathrm{~mm}$. (l) Coarse grain tailing size is $0.1-$ $0.15 \mathrm{~mm}$, and fine grain tailing size is $0.25-0.3 \mathrm{~mm}$. (m) Coarse grain tailing size is $0.15-0.25 \mathrm{~mm}$, and fine grain tailing size is $1-2 \mathrm{~mm}$. (n) Coarse grain tailing size is $0.15-0.25 \mathrm{~mm}$, and fine grain tailing size is $0.5-1 \mathrm{~mm}$. (o) Coarse grain tailing size is $0.15-0.25 \mathrm{~mm}$, and fine grain tailing size is $0.3-0.5 \mathrm{~mm}$. (p) Coarse grain tailing size is $0.15-0.25 \mathrm{~mm}$, fine grain tailing size is $0.25-0.3 \mathrm{~mm}$. (q) Coarse grain tailing size is $0.25-0.3 \mathrm{~mm}$, and fine grain tailing size is $1-2 \mathrm{~mm}$. ( $\mathrm{r}$ ) Coarse grain tailing size is $0.25-0.3 \mathrm{~mm}$, and fine grain tailing size is $0.5-1 \mathrm{~mm}$. (s) Coarse grain tailing size is $0.25-0.3 \mathrm{~mm}$, and fine grain tailing size is $0.3-0.5 \mathrm{~mm}$. ( $\mathrm{t}$ ) Coarse grain tailing size is $0.3-0.5 \mathrm{~mm}$, and fine grain tailing size is $1-2 \mathrm{~mm}$. (u) Coarse grain tailing size is $0.3-0.5 \mathrm{~mm}$, and fine grain tailing size is $0.5-1 \mathrm{~mm}$. (v) Coarse grain tailing size is $0.5-1 \mathrm{~mm}$, and fine grain tailing size is $1-2 \mathrm{~mm}$.

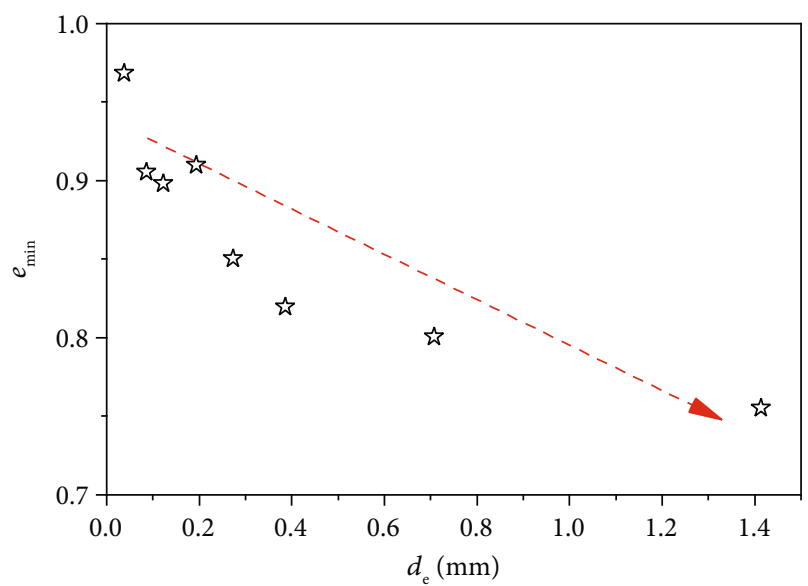

FIGURE 6: Minimum void ratio versus the equivalent size of tailing grains.

of $e_{\mathrm{d}} / e_{\mathrm{D}}$ that is approximately $0.8-1.4$ for the sand-silt soil by Chang et al. [30] has enough to cover all ranges of test results of 22 grain size patterns from 0.99 to 1.3 (Figure 7).

It was noted that different coarse grain sizes and fine grain sizes can match the same ratio of $d_{\mathrm{e}}$ and $D_{\mathrm{e}}$. In particular, the ratio of $e_{\mathrm{d}}$ and $e_{\mathrm{D}}$ varies differently from the ratio of $d_{\mathrm{e}}$ and $D_{\mathrm{e}}$, as shown in Figure 7. For example, for test samples NO • D-d and NO • E-c, they are 0.25-0.3 mm and 0.3$0.5 \mathrm{~mm}$ for coarse grain, respectively, and $0.15-0.25 \mathrm{~mm}$ and $0.25-0.3 \mathrm{~mm}$ for fine grain, respectively, as shown in the blue circles in Figure 7. The value of $d_{\mathrm{e}} / D_{\mathrm{e}}$ is 0.708 , and the values of $e_{\mathrm{d}} / e_{\mathrm{D}}$ are very close at 1.07 and 1.04, respectively. However, for test samples $\mathrm{NO} \cdot \mathrm{D}$-a and $\mathrm{NO} \cdot \mathrm{A}-\mathrm{d}$, they are 1$2 \mathrm{~mm}$ and $0.25-0.3 \mathrm{~mm}$ for coarse grain, respectively, and

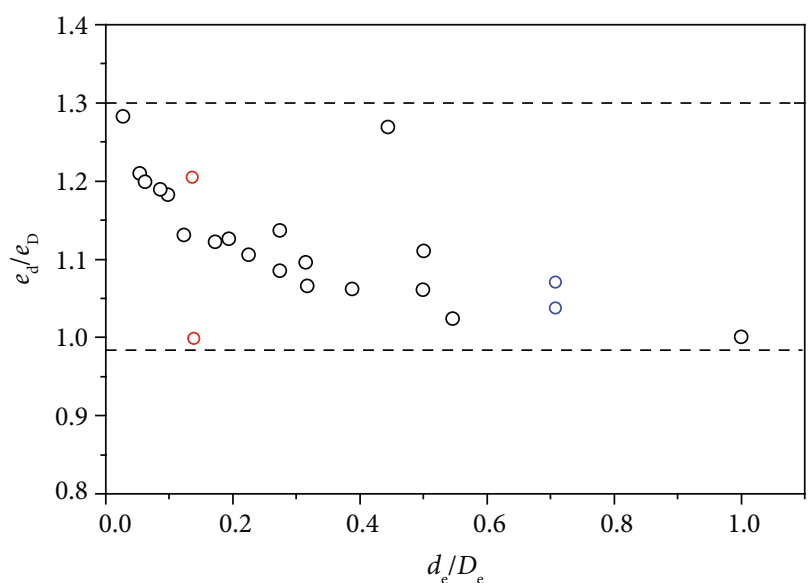

FIgURE 7: Ratio of minimum void ratio versus equivalent size ratio of tailing grains.

$0.15-0.25 \mathrm{~mm}$ and $0-0.075 \mathrm{~mm}$ for fine grain, respectively. The values of $e_{\mathrm{d}} / e_{\mathrm{D}}$ varied greatly as the value of $d_{\mathrm{e}} / D_{\mathrm{e}}$ was nearly 0.138; as shown in the red circles in Figure 7 , they are 0.999 and 1.205 , respectively. The reason that caused differences is coarse grain size is sand for both of the two test samples, but for fine grain size, one grain type is sand and the other is silt-clay. The value of $e_{\mathrm{d}} / e_{\mathrm{D}}$ is higher for siltclay grain size than that for sand grain size. This is agreement with what was observed by Chang et al. [30], Chang and Deng [42], and Liu et al. [33] for sand-silt soils and granular soils. The reason causing this phenomenon was the difference in grain shape, wherein it was found that the shape of grains changes with decreasing size from rotund or angular to plate or acicular. 


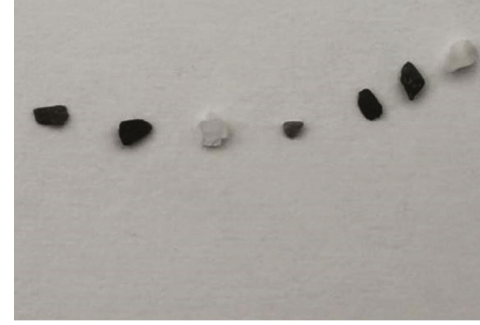

(a)

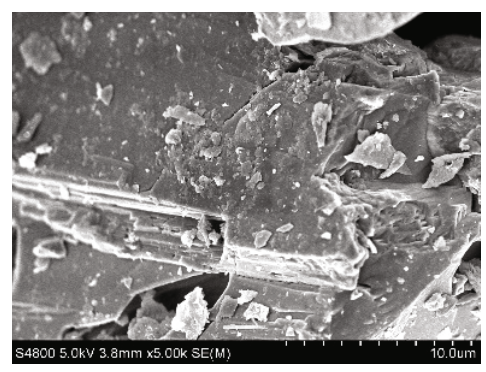

(c)

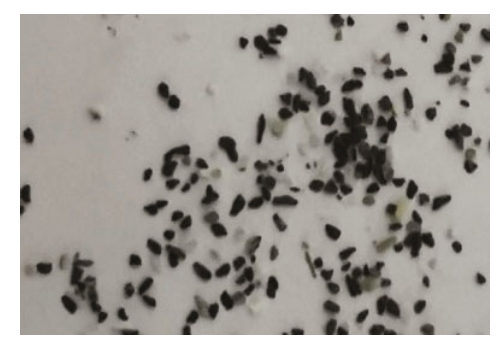

(b)

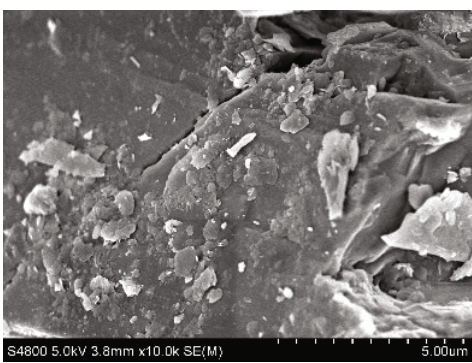

(d)

FIGURE 8: Images of grain shape with different grain size of tailing deposits. (a) Tailing sand with a size of 0.5-1 mm. (b) Tailing sand with a size of 0.1-0.15 mm. (c) Tailing silt and clay magnified 5000x in SEM. (d) Tailing silt and clay magnified 10000x in SEM.

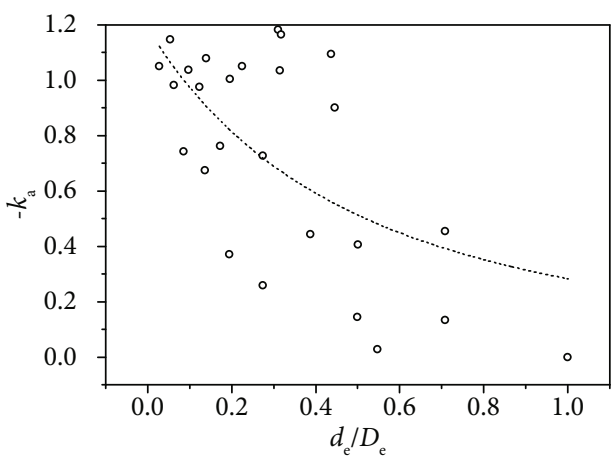

(a)

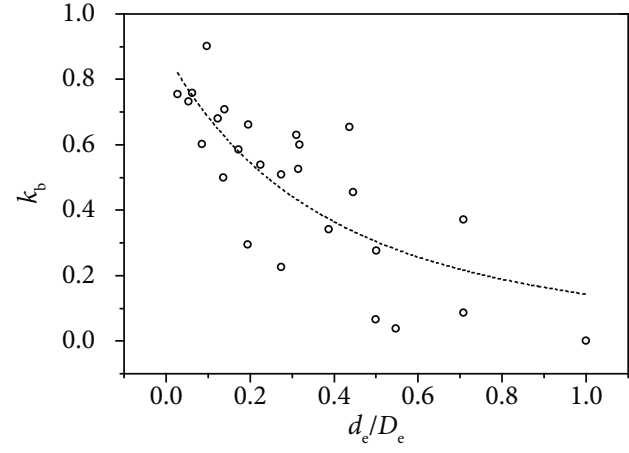

(b)

Figure 9: Measured slopes from experimental results for tailing deposits of 25 grain size patterns. (a) $-k_{\mathrm{a}}$; (b) $k_{\mathrm{b}}$.

As expected for tailings, silt-clay grains are usually platy, acicular (needle), or schist, whereas sand grains are usually subangular or angular, or subrotund in shape for a very few, as shown in Figure 8. Chang et al. [41] have verified that the grain shape has noteworthy influence on the minimum void ratio, and the values for subangular or angular grains are higher than those for spherical grains. It is logical that the minimum void ratio is in the range of $0.76-1$ for the monosized grains of tailings compared with those of soil (Figure 6). Furthermore, comparing two patterns of siltclay-sand tailings and fine-coarse sand tailings, different shapes of grains may be another reason for the values of minimum void ratio out of the inverted triangle range. This means that the grain shape has noteworthy influence on the value of minimum void ratio, but not on the triangle rule of relationship between void ratio and fine content, which is consistent with the research results in Ref. [29] and in those of Chang et al. [30].
We can therefore conclude that equivalent grain size ratio and shape characteristics are the main factors affecting the values of minimum void ratio for tailings, and in addition, the trend of minimum void ratio for tailings in different fine content $\left(-k_{\mathrm{a}}\right.$ and $\left.k_{\mathrm{b}}\right)$ is also influenced by dominant grain size and equivalent grain size ratio $\left(d_{\mathrm{e}} / D_{\mathrm{e}}\right)$.

3.3. Parameter Calibration. Obtained from equation (17) and equation (18), the term $d e_{\min } / d x_{2}$ represents $k_{\mathrm{a}}$ and $k_{\mathrm{b}}$, respectively, the same as the slope of MO and NO shown in Figure 3. They can be determined directly from the experimental result in Figure 5; thus, the values of $-k_{\mathrm{a}}$ and $k_{\mathrm{b}}$ in 22 grain size patterns can be obtained as shown in symbols in Figure 9. The average trends of $-k_{\mathrm{a}}$ and $k_{\mathrm{b}}$ versus equivalent grain size ratio $\left(d_{\mathrm{e}} / D_{\mathrm{e}}\right)$ are marked as the short dot lines in Figure 9. The value range of the equivalent grain size ratio $\left(d_{\mathrm{e}} / D_{\mathrm{e}}\right)$ is between 0 and 1 . According to equation (17) and equation (18), the trends of the data points of $\varepsilon$ and $\omega$ are 


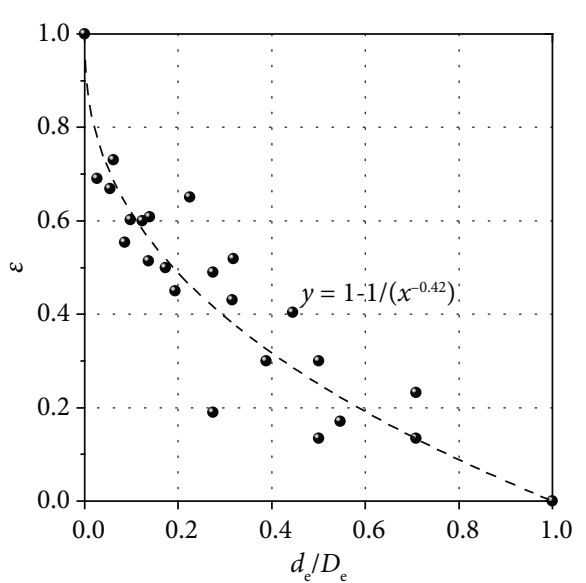

(a)

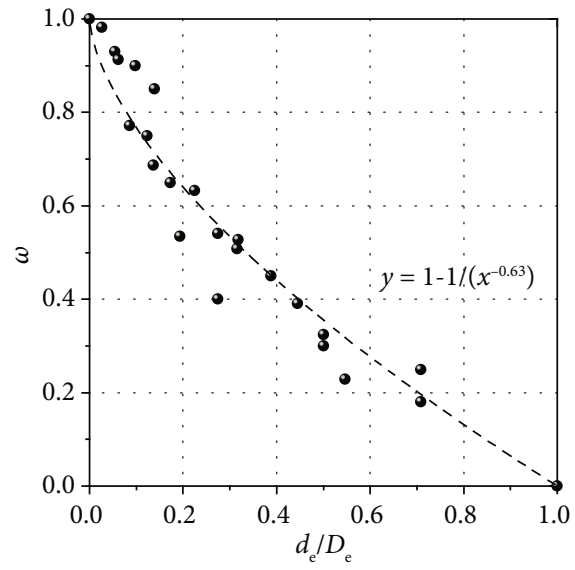

(b)

Figure 10: Coefficients $\varepsilon$ and $\omega$ for tailing deposits of 25 grain size patterns. (a) $\varepsilon$; (b) $\omega$.

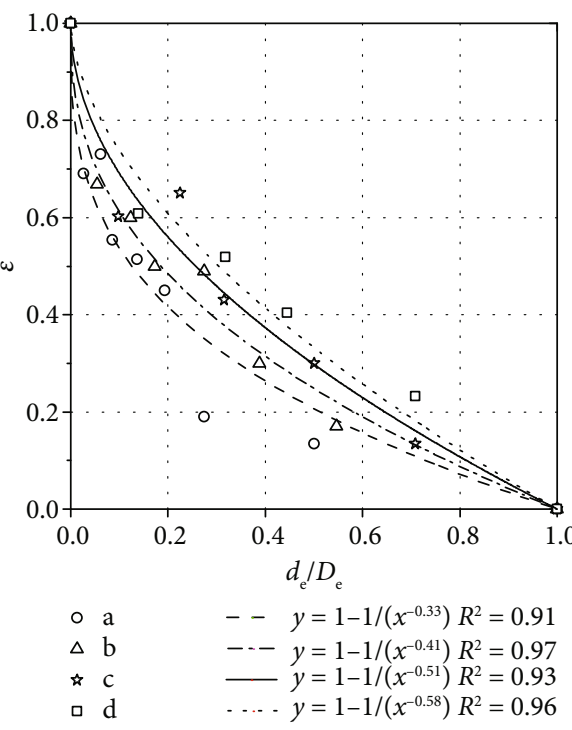

(a)

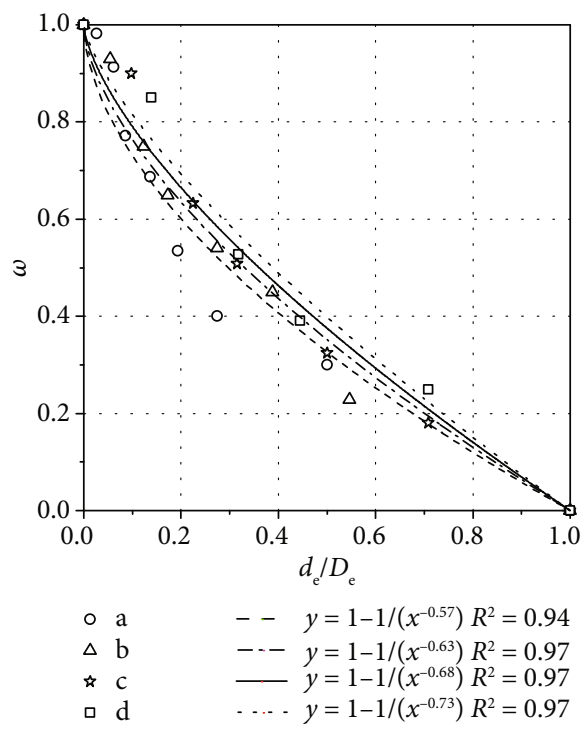

(b)

FIGURE 11: Result of coefficients $\varepsilon$ and $\omega$ for coarse-grain-dominant binary grain size tailing deposits. (a) $\varepsilon$; (b) $\omega$.

similar to those of $-k_{\mathrm{a}}$ and $k_{\mathrm{b}}$; only the value of the horizontal and vertical axes are both within 0-1 (Figure 10). Drawing the trends of $\varepsilon$ and $\omega$ as the dashed lines in Figure 10, the values are high (steep) at small $d_{\mathrm{e}} / D_{\mathrm{e}}$. With the increase of $d_{\mathrm{e}} / D_{\mathrm{e}}$, both slopes decrease in value (becomes less steep). Data of $\varepsilon$ and $\omega$ are fitting by a power function of $d_{\mathrm{e}} / D_{\mathrm{e}}$, given as follows:

$$
\begin{gathered}
\varepsilon=1-\left(\frac{D_{\mathrm{e}}}{d_{\mathrm{e}}}\right)^{q}, \\
\omega=1-\left(\frac{D_{\mathrm{e}}}{d_{\mathrm{e}}}\right)^{s} .
\end{gathered}
$$

The two parameters $\varepsilon$ and $\omega$ are functions of the grain size of binary grain size tailing, and the exponents $q$ and $s$ are -0.42 and -0.63 , respectively.
However, as discussed in the previous section, similar as $-k_{\mathrm{a}}$ and $k_{\mathrm{b}}$, except $d_{\mathrm{e}} / D_{\mathrm{e}}$, parameters $\varepsilon$ and $\omega$ can also be governed by dominant grain size.

To assess the impact of dominant grain size on parameters $\varepsilon$ and $\omega$, the selected tailings were classified into two categories: the first are the binary grain size tailings that are coarse dominant, and the second are the binary grain size tailings that are fine dominant.

For different dominant grains, using equation (20) and equation (21), the values of parameters $q$ and $s$ were calibrated by best fitting the values of $\varepsilon$ and $\omega$ versus different equivalent grain size ratios $\left(d_{\mathrm{e}} / D_{\mathrm{e}}\right)$. The best fitting curves are shown in Figures 11 and 12, and Table 2 presents the result coefficients $q$ and $s$ and coefficient of determination $R^{2}$.

For binary grain size tailings that are coarse dominant, the values of exponents $q$ and $s$ increase with expanding dominant grain size and the coefficient of determination 


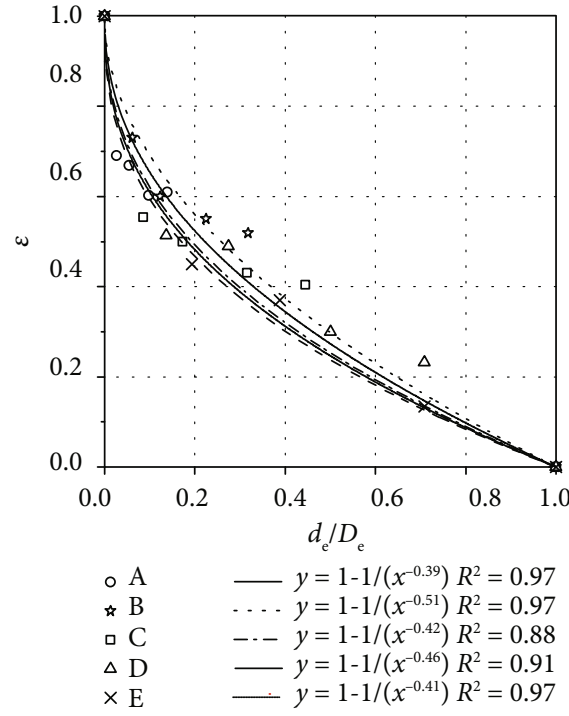

(a)

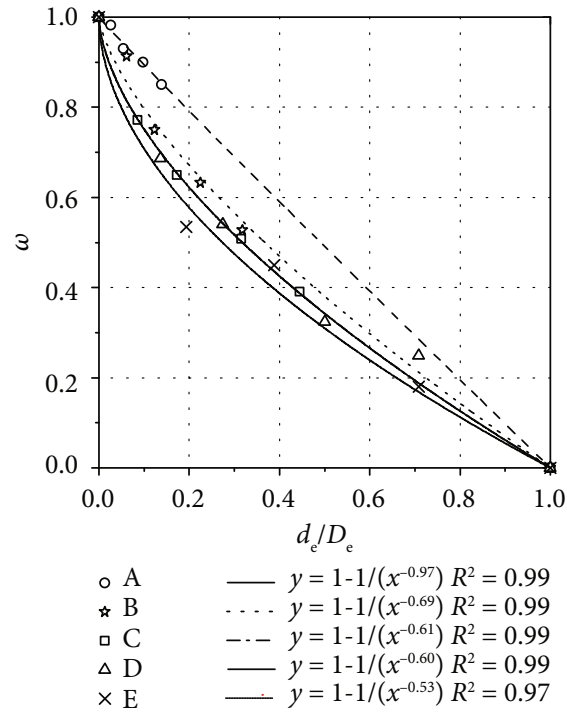

(b)

FIGURE 12: Result of coefficients $\varepsilon$ and $\omega$ for fine-grain-dominant binary grain size tailing deposits. (a) $\varepsilon$; (b) $\omega$.

TABLE 2: Scheme of the experiments.

\begin{tabular}{|c|c|c|c|c|c|c|c|c|c|c|c|}
\hline \multicolumn{6}{|c|}{ Tailing mixture affected by fine } & \multicolumn{6}{|c|}{ Tailing mixture affected by coarse } \\
\hline \multirow{2}{*}{$\mathrm{D} / \mathrm{mm}$} & \multirow{2}{*}{ Test sample nos. } & \multicolumn{2}{|c|}{$\varepsilon$} & \multicolumn{2}{|c|}{$\omega$} & \multirow{2}{*}{$d / \mathrm{mm}$} & \multirow{2}{*}{ Test sample nos. } & \multicolumn{2}{|c|}{$\varepsilon$} & \multicolumn{2}{|c|}{$\omega$} \\
\hline & & $q$ & $R^{2}$ & $s$ & $R^{2}$ & & & $q$ & $R^{2}$ & $s$ & $R^{2}$ \\
\hline $1-2$ & $N-\mathrm{a}$ & -0.33 & 0.91 & -0.57 & 0.94 & $0.25-0.3$ & E- $n$ & -0.41 & 0.97 & -0.53 & 0.97 \\
\hline $0.5-1$ & $N-\mathrm{b}$ & -0.41 & 0.97 & -0.63 & 0.97 & $0.15-0.25$ & $\mathrm{D}-n$ & -0.46 & 0.91 & -0.60 & 0.99 \\
\hline $0.3-0.5$ & $N-\mathrm{c}$ & -0.51 & 0.93 & -0.68 & 0.97 & $0.1-0.15$ & $\mathrm{C}-n$ & -0.42 & 0.88 & -0.61 & 0.99 \\
\hline $025=0$ & $N-d$ & 058 & 096 & 073 & 097 & $0.075-0.1$ & B- $n$ & -0.51 & 0.97 & -0.69 & 0.99 \\
\hline $0.25-0.3$ & $N-\mathrm{d}$ & -0.58 & 0.96 & -0.13 & 0.97 & $0-0.075$ & A- $n$ & -0.39 & 0.97 & -0.97 & 0.99 \\
\hline
\end{tabular}

$R^{2}=0.91-0.97$. As shown from the fitting curves of binary grain size tailings that are fine dominant in Figure 12, the value of exponents $q$ and $s$ increase with dominant grain size becoming larger for fine-coarse sand tailings (E- $n, \mathrm{D}-n, \mathrm{C}-n$, and $\mathrm{B}-n)$. And, we may observe that the exponents are smaller for $q$ and larger for $s$ when there is a more contrast of dissimilarity between the coarse and fine grain shapes for binary grain size tailings, clearly shown in the fitting curves of "A-" in Figure $12(q=-0.39, s=-0.97)$. The differences have been explained in Figure 8 as silt-clay-sand tailings have more contrast of dissimilarity between its platy, acicular, or schist grains, than the dissimilarity of finecoarse sand tailings, which consist of subrotund or subangular sand.

Clearly, except for the influence of dominant grain size and equivalent grain size ratio of tailing mixtures, the values of exponents mean that the rates of change of $q$ and $s$ vary when affected by the grain shape. For both two categories of tailings, a smaller dominant grain size imply smaller values of exponents ( $q$ and $s$ ). The exponents for silt-claysand tailings are the only exception; the exponents seem to change without fitting the above law due to the difference in grain shape of tailings. This explanation seems to be in agreement with the test results for silt-sand soil mixtures in Chang et al. [30].

3.4. Model Verification. Using these fitted values, parameters $\varepsilon$ and $\omega$ for different dominant grain size can be determined by equation (20) and equation (21). Therefore, the minimum void ratios for all the binary size tailings can be computed. The predicted and measured void ratios are compared in Figure 13. It can be seen that the predicted values are in good agreement with the measured ones. The average discrepancies between predicted and measured void ratios are no more than $10 \%$. This suggests a good performance of the different grain size of tailings for the predicted exponents ( $q$ and $s$ ).

In terms of the fitted values, the prediction of optimal fine content values $\left(X_{2}, \%\right)$, as expected, are in the range of $30 \%-42.3 \%$, basically within the range of measurements (20\%-40\%). And the optimal void ratios corresponding to these predicted values are plotted in Figure 14 for two categories of tailings (the fine dominant one and the coarse dominant one).

It can be observed that regardless of the differences in exponents for different dominant grain sizes, grain shapes, 


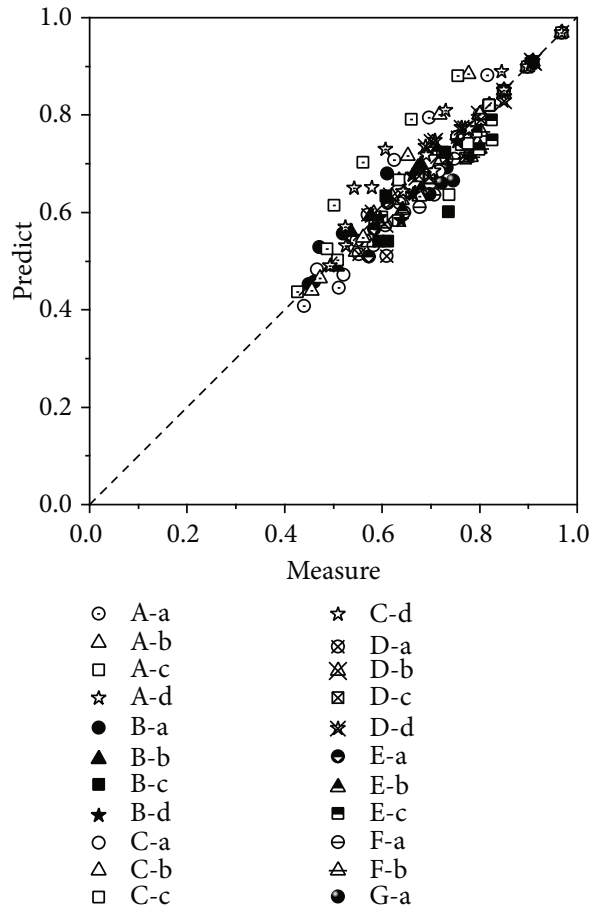

(a)

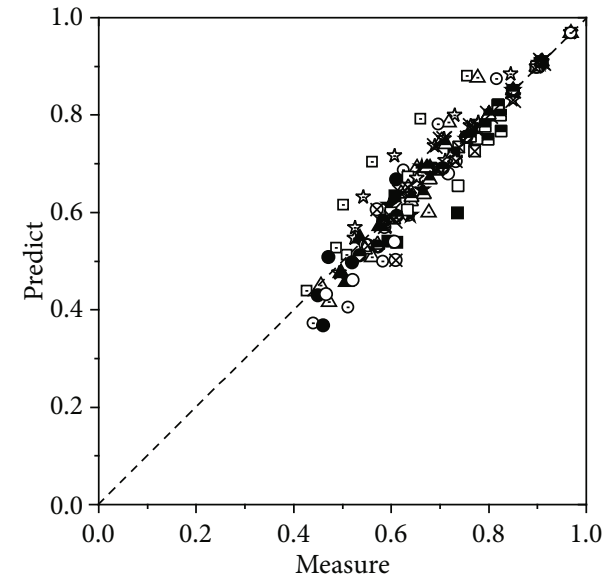

\begin{tabular}{|c|c|}
\hline$\odot \quad A-a$ & t5 \\
\hline$\Delta \mathrm{A}-\mathrm{b}$ & $\otimes$ \\
\hline$\square \quad A-c$ & $\not$ \\
\hline A-d & $\Delta$ \\
\hline - $\mathrm{B}-\mathrm{a}$ & $*$ \\
\hline$\Delta \mathrm{B}-\mathrm{b}$ & $\bullet$ \\
\hline - B-c & $\Delta$ \\
\hline * B-d & E \\
\hline C-a & $\theta$ \\
\hline C-b & $\theta$ \\
\hline C-c & - \\
\hline
\end{tabular}

FIGURE 13: Comparison of measured and predicted results for tailing deposits of 23 grain size patterns. (a) Coarse-grain-dominant tailing deposits. (b) Fine-grain-dominant tailing deposits.

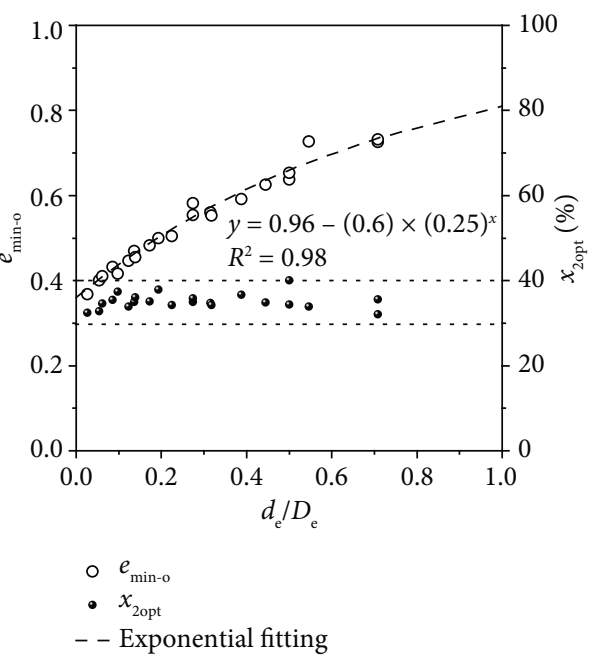

(a)

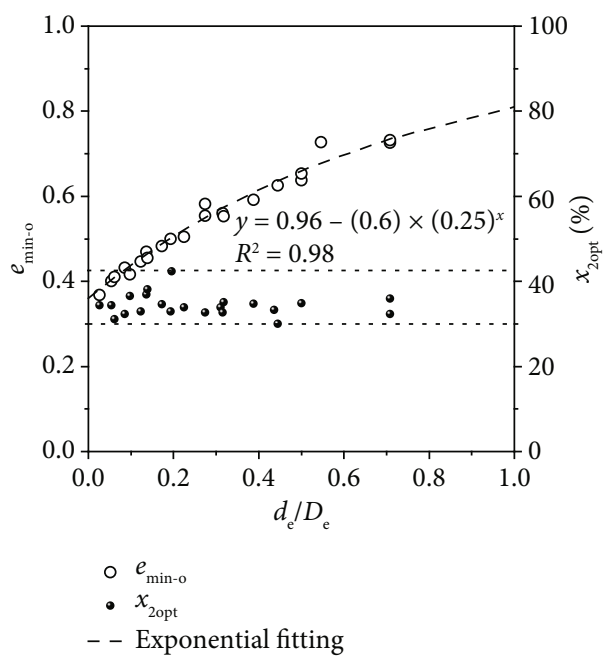

(b)

Figure 14: Predicted results of optimum fine content and optimum minimum void ratio for tailing deposits of 25 grain size patterns. (a) Coarse-grain-dominant tailing deposits. (b) Fine-grain-dominant tailing deposits.

and equivalent grain size ratios, the trends of optimal void ratios can also be well described by the same exponential function of equivalent grain size ratio, as follows:

$$
e_{\text {min-o }}=0.96-\frac{3}{5}\left(\frac{1}{4}\right)^{D_{\mathrm{e}} / d_{\mathrm{e}}}
$$

Thus, the most significant parameters in determining the optimal void ratios are the equivalent grain size ratio. The optimal void ratios increase with the equivalent grain size ratio rising, and this has a value range of $0.35-0.8$. Viewing the minimum void ratio from Figure 6, it is not greater than 0.76 for the monosized grain. And for the mixture of tailings shown in Figure 5, the minimum void ratio is not less than 
0.4. The optimal void ratio, as expected, basically conforms to the measured results.

\section{Conclusions}

The grains of tailings distribution in the reservoir area are disordered with a large void ratio and poor drainage. In this paper, we simplified grain size composition into two kinds, coarse and fine, and assumed that the reduction in the minimum void ratio is due to the grain rearrangement. A minimum void ratio model for tailing grain in binary size was developed for predicting the minimum void ratio, optimal void ratio, and optimal fine content, requiring only two parameters, $\varepsilon$ and $\omega$. Using data regularity of 22 grain size patterns of tailings (about 168 samples with various fine contents), we observed that, for tailings, the minimum void ratio values versus fine content conform to the triangle rule predicted by the model, and the measured datum are significantly affected by equivalent grain size ratio, dominant grain size, and shape characteristics. The data of $\varepsilon$ and $\omega$ by measured results are fitting by power function, and the exponent values increase with the dominant grain size expanded.

With the results of above function, the proposed model was verified with respect to tailings. Comparisons showed that the predicted results were in good agreement with the experimental ones. The average discrepancies are less than $10 \%$. The predicted optimal fine content values are in the range of $30 \%-42.3 \%$ within the range of measurements. The predicted optimal void ratio varies exponentially with the equivalent grain size ratio, completely unaffected by dominant grain size and shape characteristics. The predicted values (between 0.35 and 0.8 ) were in good agreement with the experimental ones (with 0.4-0.76). Therefore, for different grain size ratios, the optimal void ratio may be predicted for further safety of tailings.

\section{Abbreviations}

\begin{tabular}{|c|c|}
\hline$V_{\mathrm{V}}, V_{\mathrm{V} 1}, V_{\mathrm{V} 2}:$ & $\begin{array}{l}\text { Void spaces for the mixture, the coarse } \\
\text { grains, and the fine grains }\end{array}$ \\
\hline$V_{\mathrm{G}}, V_{\mathrm{G} 1}, V_{\mathrm{G} 2}:$ & $\begin{array}{l}\text { Solid grains for the mixture, the coarse } \\
\text { grains, and the fine grains }\end{array}$ \\
\hline$x_{1}, x_{2}:$ & $\begin{array}{l}\text { Volume fractions for coarse grains or fine } \\
\text { grains, respectively }\end{array}$ \\
\hline$e_{1}, e_{2}:$ & $\begin{array}{l}\text { The minimum void ratios of monosized } \\
\text { grain fraction }\end{array}$ \\
\hline$e_{\min }:$ & The minimum void ratio \\
\hline$\alpha, \beta$ & $\begin{array}{l}\text { A material constant to describe the alter- } \\
\text { ation due to diminished void spaces and the } \\
\text { expanded solid volume for coarse grain } \\
\text { general status and fine grain general status }\end{array}$ \\
\hline$k_{\mathrm{a}}$ and $k_{\mathrm{b}}$ : & $\begin{array}{l}\text { The slope of line } \mathrm{MO} \text { and line } \mathrm{NO} \text { that } \\
\text { expresses the minimum void ratio versus } \\
\text { fine content of tailings }\end{array}$ \\
\hline$e_{\min -\mathrm{o}}:$ & $\begin{array}{l}\text { Optimal void ratio denoted as the lowest } \\
\text { value of the minimum void ratio }\end{array}$ \\
\hline$x_{2 \text { opt }}:$ & Optimal fine content \\
\hline
\end{tabular}

$\varepsilon$ and $\omega: \quad$ Two variates are set between 0 and 1 , which are termed as the filling coefficient and the embedment coefficient, respectively

$d_{\mathrm{e}}, d_{\max }, d_{\min }$ : The equivalent size, the maximum grain size, and the minimum grain size of tailing fine grains

$D_{\mathrm{e}}, D_{\max }, D_{\min }:$ The equivalent size, the maximum grain size, and the minimum grain size of tailing coarse grains

$d_{\mathrm{e}} / D_{\mathrm{e}}: \quad$ Equivalent grain size ratio of fine and coarse grains

$e_{\mathrm{d}} / e_{\mathrm{D}}: \quad$ The minimum void ratio of equivalent grain size for fine and coarse grains

$q, s: \quad$ The coefficients of exponent functions of $\varepsilon$ and $\omega$.

\section{Data Availability}

The data used to support the findings of this study are included within the article.

\section{Conflicts of Interest}

The authors declare that there is no conflict of interest regarding the publication of this paper.

\section{Acknowledgments}

This work was supported by the National Natural Science Foundation of China (Nos. 41907255, 41602359, 41702298, and 41807190), the Natural Science Basic Research Plan in Shaanxi Province of China (No. 2017JQ4019), and the Key Laboratory of the Northern Qinghai-Tibet Plateau Geological Processes and Mineral Resources (No. 2019-KY-01).

\section{References}

[1] S. Azam and Q. Li, "Tailings dam failures: a review of the last one hundred years," Geotechnical News, vol. 28, no. 4, pp. 5053, 2010.

[2] M. P. Davis, "Tailings impoundment failures: are geotechnical engineers listening?," in Geotechnical News, pp. 31-36, Bi Tech Publishers, Richmond, BC, Canada, 2002.

[3] B. Ferdosi, M. James, and M. Aubertin, "Effect of waste rock inclusions on the seismic stability of an upstream raised tailings impoundment: a numerical investigation," Canadian Geotechnical Journal, vol. 52, no. 12, pp. 1930-1944, 2015.

[4] E. J. Klohn, "Tailings dams in Canada," in Geotechnical News, pp. 117-123, Bi Tech Publishers, Richmond, BC, Canada, 1997.

[5] P. N. Psarropoulos and Y. Tsompanakis, "Stability of tailings dams under static and seismic loading," Canadian Geotechnical Journal., vol. 45, no. 5, pp. 663-675, 2008.

[6] M. Rico, G. Benito, A. R. Salgueiro, A. Díez-Herrero, and H. G. Pereira, "Reported tailings dam failures: a review of the European incidents in the worldwide context," Journal of Hazardous Materials, vol. 152, no. 2, pp. 846-852, 2008.

[7] L. H. Silva Rotta, E. Alcântara, E. Park et al., "The 2019 Brumadinho tailings dam collapse: possible cause and impacts of the worst human and environmental disaster in Brazil," 
International Journal of Applied Earth Observation and Geoinformation, vol. 90, article 102119, 2020.

[8] L. Hu, H. Wu, L. Zhang, P. Zhang, and Q. Wen, "Geotechnical properties of mine tailings," Journal of Materials in Civil Engineering, vol. 29, no. 2, article 04016220, 2017.

[9] M. Liew, M. Xiao, S. Liu, and D. Rudenko, "In situ seismic investigations for evaluating geotechnical properties and liquefaction potential of fine coal Tailings," Engineering, vol. 146, no. 5, article 04020014, 2020.

[10] S. T. Pan, A research on the Stability of Baogang Tailing Dam, [M.S. thesis], China university of geosciences, Beijing, 2010.

[11] Y. J. Mi, Experimental Study on Permeability of Fengshuigou Tailing Sand and Its Seepage Simulation, [M.S. thesis], University of Science and Technology Liaoning. Fuxin, 2018.

[12] X. Hu, T. Oommen, Z. Lu, T. Wang, and J. W. Kim, "Consolidation settlement of Salt Lake County tailings impoundment revealed by time-series InSAR observations from multiple radar satellites," Remote Sensing of Environment., vol. 202, pp. 199-209, 2017.

[13] J. X. Jin, C. G. Song, B. Liang, Y. Chen, and M. Su, "Dynamic characteristics of tailings reservoir under seismic load," Environmental Earth Sciences., vol. 77, no. 18, pp. 654.1-654.11, 2018.

[14] X. Z. Yu, "Application of 3D solid water seepage method in construction of fine fraction tailings dam," Chinese Journal of Geotechnical Engineering, vol. 38, no. S1, pp. 74-78, 2016.

[15] C. Zhang, C. K. Ma, C. H. Yang, Q. L. Chen, and Z. K. Pan, "Effects of particle diameter on shear strength of tailings and stability of tailings dams," Chinese Journal of Geotechnical Engineering, vol. 41, Supplement 1, pp. 145-148, 2019.

[16] J. Kim, T. Kawai, and M. Kazama, "Minimum void ratio characteristic of soils containing non-plastic fines," Soils and Foundations., vol. 59, no. 6, pp. 1772-1786, 2019.

[17] S. Liu, Y. Wang, and D. Feng, "Experimental study on drainage characteristics of new composite drainage pipes in tailings pond," Chinese Journal of Geotechnical Engineering, vol. 41, no. 12, pp. 2360-2366, 2019.

[18] X. P. Peng, X. C. Yang, and L. J. Guo, "Experimental study on the hindered settling process of backfill tailings," Journal of China Coal Society, vol. 44, no. 5, pp. 1521-1526, 2019.

[19] K. Miura, K. Maeda, M. Furukawa, and S. Toki, "Physical characteristics of sands with different primary properties," Soils and Foundations, vol. 37, no. 3, pp. 53-64, 1997.

[20] K. Okuyama, M. Fujiwara, H. Ochi, and M. Inoue, "Expansion of maximum particle size limitation value in test for maximum and minimum densities of sands," Doboku Gakkai Ronbunshu, vol. 1999, no. 638, pp. 11-27, 1999.

[21] M. Cubrinovski and K. Ishihara, "Maximum and minimum void ratio characteristics of sands," Soils and Foundations, vol. 42, no. 6, pp. 65-78, 2002.

[22] X. Zhang, E. C. Zhai, D. A. Sun, Y. J. Wu, and Y. T. Lu, "Theoretical and numerical analyses on hydro-thermal-saltmechanical interaction of unsaturated salinized soil subjected to typical unidirectional freezing process," International Journal of Geomechanics, vol. 21, no. 7, article 04021104, 2021.

[23] Z. Q. Zhang, Q. B. Wu, G. L. Jiang, S. Gao, J. Chen, and Y. Z. Liu, "Changes in permafrost temperatures from 2003 to 2015 on the Qinghai-Tibet Plateau," Cold Region Science and Technology, vol. 169, article 102904, 2020.

[24] Z. Q. Zhang, Q. B. Wu, M. T. Hou, B. W. Tai, and Y. K. An, "Permafrost change in Northeast China in the 1950s-2010s,"
Advances in Climate Change Research, vol. 12, no. 1, pp. 1828, 2021.

[25] Z. Xia, R. P. Chen, and X. Kang, "Laboratory characterization and modelling of the thermal-mechanical properties of binary soil mixtures," Soils and Foundations, vol. 59, no. 6, pp. 21672179, 2019.

[26] G. C. Cho, J. Dodds, and J. C. Santamarina, "Particle shape effects on packing density, stiffness, and strength: natural and crushed sands," Journal of Geotechnical and Geoenvironmental Engineering, vol. 132, no. 5, pp. 591-602, 2006.

[27] Y. Yilmaz, "A study on the limit void ratio characteristics of medium to fine mixed graded sands," Engineering Geology, vol. 104, no. 3-4, pp. 290-294, 2009.

[28] F. Weishui, Studies on the Stability of Tailings Dam, [Ph.D. thesis], Faculty of Civil Engineering and Architecture. Kunming University of Science and Technology, 2012.

[29] T.-T. Ng, W. Zhou, G. Ma, and X.-L. Chang, "Macroscopic and microscopic behaviors of binary mixtures of different particle shapes and particle sizes," International Journal of Solids \& Structures, vol. 135, pp. 74-84, 2018.

[30] C. S. Chang, J. Y. Wang, and L. Ge, "Modeling of minimum void ratio for sand-silt mixtures," Engineering Geology, vol. 196, pp. 293-304, 2015.

[31] F. Larrardde, Concrete Mixture Proportioning: A Scientific Approach, Taylor \& Francis. CRC Press, London, 1999.

[32] Z. Duan, W. C. Cheng, J. B. Peng, M. M. Rahman, and H. Tang, "Interactions of landslide deposit with terrace sediments: perspectives from velocity of deposit movement and apparent friction angle," Engineering Geology, vol. 280, article 105913, 2021.

[33] Z. R. Liu, W. M. Ye, Z. Zhang, Q. Wang, Y. G. Chen, and Y. J. Cui, "A nonlinear particle packing model for multi-sized granular soils," Construction \& Building Materials, vol. 221, pp. 274-282, 2019.

[34] M. M. Monkul and G. Ozden, "Compressional behavior of clayey sand and transition fines content," Engineering Geology, vol. 89, no. 3-4, pp. 195-205, 2007.

[35] R. H. Kuerbis, The Effect of Gradation and Fines Content in the Undrained Loading Response of Sand,. [Ph.D. thesis], University of British Columbia, Vancouver, Canada, 1989.

[36] S. Thevanayagam, "Effect of fines and confining stress on undrained shear strength of silty sands," Journal of Geotechnical and Geoenvironmental Engineering, vol. 124, no. 6, pp. 479-491, 1998.

[37] S. Thevanayagam and S. Mohan, "Intergranular state variables and stress-strain behaviour of silty sands," Geotechnique, vol. 50, no. 1, pp. 1-23, 2000.

[38] S. Thevanayagam, T. Shenthan, S. Mohan, and J. Liang, "Undrained fragility of clean sands, silty sands, and sandy silts," Journal of Geotechnical and Geo-environmental Engineering, vol. 128, no. 10, pp. 849-859, 2002.

[39] S. Thevanayagam, "Intergrain contact density indices for granular mixes," Earthquake Engineering \& Engineering Vibration, vol. 6, no. 2, pp. 123-146, 2007.

[40] R. C. Chaney, K. R. Demars, P. V. Lade, C. D. Liggio, and J. A. Yamamuro, "Effects of non-plastic fines on minimum and maximum void ratios of sand," Geotechnical Testing Journal., vol. 21, no. 4, pp. 336-347, 1998.

[41] C. S. Chang, J. Y. Wang, and L. Ge, "Maximum and minimum void ratios for sand-silt mixtures," Engineering Geology, vol. 211, pp. 7-18, 2016. 
[42] C. S. Chang and Y. Deng, "A nonlinear packing model for multi-sized particle mixtures," Powder Technology, vol. 336, pp. 449-464, 2018.

[43] Z. Xia, X. Liu, and J. Gu, "Laboratory investigation and modelling of the thermal-mechanical properties of soil in shallow mineralized groundwater area," Geofluids, vol. 2019, Article ID 5121740, 21 pages, 2019.

[44] B. Zhang, Dynamic Properties of the Saturation Tailing and Dynamic Stability Analysis of the Tailing Dam, [M.S. thesis], Shi Jia-zhuang Tiedao University, 2013.

[45] L. Qiao, C. L. Qu, and M. Cui, "Effect of fines content on engineering characteristics of tailings," Rock and Soil Mechanics, vol. 36, no. 4, pp. 923-927+945, 2015.

[46] Q. G. Zhang, Y. M. Wang, G. Z. Li et al., "Simulation of the mesomechanics mechanism of the tailing dam's deformation with particle flow code," Journal of Chongqing University, vol. 38, no. 3, pp. 71-79, 2015.

[47] S. W. Wu, C. H. Yang, and C. Zhang, "Particle size distribution of fine-grained tailings based on Weibull distribution," Journal of Chongqing University, vol. 39, no. 3, pp. 1-12, 2016.

[48] S. Bau, C. Dazon, O. Rastoix, and N. Bardin-Monnier, "Effect of constituent particle polydispersion on VSSA-based equivalent particle diameter: theoretical rationale and application to a set of eight powders with constituent particle median diameters ranging from 9 to $130 \mathrm{~nm}$," Advanced Powder Technology, vol. 32, no. 5, pp. 1369-1379, 2021.

[49] J. Q. Ma, H. Peng, S. B. Li, Z. Duan, X. Zhang, and D. Ma, "Exploring the occurrence of clogging in highly permeable coarse soils of dam foundations," Advances in Civil Engineering, vol. 2020, no. 3, p. 16, 2020. 